\title{
The multiple dimensions of race
}

\author{
Wendy D. Roth \\ Sociology Department, University of British Columbia, Vancouver, Canada
}

This is an Accepted Manuscript of an article published by Taylor \& Francis in Ethnic and Racial Studies in March 2016, available online: http://www.tandfonline.com/doi/full/10.1080/01419870.2016.1140793

The citation is:

Roth, Wendy D. 2016. “The Multiple Dimensions of Race.” Ethnic and Racial Studies 39(8): 1310-1338.

\begin{abstract}
Increasing numbers of people in the United States and beyond experience "race" not as a single, consistent identity but as a number of conflicting dimensions. This article distinguishes the multiple dimensions of the concept of race, including racial identity, selfclassification, observed race, reflected race, phenotype, and racial ancestry. With the word "race" used as a proxy for each of these dimensions, much of our scholarship and public discourse is actually comparing across several distinct, albeit correlated, variables. Yet which dimension of race is used can significantly influence findings of racial inequality. I synthesize scholarship on the multiple dimensions of race, and situate in this framework distinctive literatures on colorism and genetic ancestry inference. I also map the relationship between the multidimensionality of race and processes of racial fluidity and racial boundary change.
\end{abstract}

KEYWORDS Self-classification; interviewer-classification; skin color; phenotype; ancestry; race components

This article synthesizes a growing body of scholarship that distinguishes and analyzes the multiple dimensions of the concept of race as experienced by individuals and as measured in research. Increasing numbers of people in the United States and beyond experience "race" not as a single, consistent identity but as a number of conflicting dimensions. These may include, for instance, how an individual self-identifies her race, how she is perceived by others, how she believes she is perceived by others, what she checks among the limited options on the census or other surveys, her skin color and other aspects of her racial appearance, and her racial ancestry. These dimensions influence one another, but are not necessarily the same. For example, Salvador, a restaurant worker in New York, identifies his race as Puerto Rican. Phenotypically, he is dark- 
skinned with indigenous features, leading some Americans to view him as Black. He believes that Americans view him as Hispanic, based on his accent and name. Yet on the census, Salvador checks White for his race because no listed option fits his identity and in Puerto Rico his mixed racial ancestry allowed him to consider himself closer to White than to Black (Roth 2010). The word "race" tends to be used as a proxy for each of these dimensions, with the result that much of our scholarship, as well as public discourse, is actually comparing across several distinct, albeit correlated, variables.

An important contribution of this scholarship is to emphasize that no single dimension is a person's "true" or "correct" race. For instance, observers' classifications may not match the individuals' self-identification, yet each of these dimensions measures something different about the way that individuals experience race in their daily lives. When it comes to housing or employment discrimination, Salvador's perception and treatment as Black is the meaningful reality, regardless of the fact that those observers are not correctly guessing the way he views himself. We can understand race as a cognitive structure that divides people into hierarchically ordered categories on the basis of certain physical or biological characteristics that are believed to be inherent (Roth 2012). An individual's race is shaped by both her own identification and the attributions and reactions of others (Cooley 1902; Jenkins 2008). By deconstructing race into its diverse dimensions, this scholarship illustrates precisely how race is socially constructed, by highlighting the micro-level processes and interactions that build, maintain, and occasionally shift a cognitive structure of race.

Much of the literature that explicitly addresses the multiple dimensions of race focuses on the United States, where demographic changes such as immigration and interracial marriage have led to increasing numbers of people experiencing conflicting dimensions of race. This is particularly true for groups such as Latinos and the multiracial population (Golash-Boza and Darity 2008; Harris and Sim 2000; Hitlin, Brown, and Elder 2007; Rockquemore and Brunsma 2002; Roth 2010). Native Americans are another group where dimensions of race are frequently inconsistent (Bratter and Gorman 2011; Campbell and Troyer 2007). Some also find inconsistencies for Asians and Middle Easterners (Boehmer et al. 2002; Vargas and Stainback In press), and even some White and Black Americans - two groups for whom racial classification is assumed to be fairly static (Kressin et al. 2003; Noymer, Penner, and Saperstein 2011; Saperstein 2006). Distinct dimensions of race have also been examined in Latin America, where there has long been awareness of discrepancies between color, ancestry, and racial classification, for example (Bailey, Fialho, and Penner In press; Cabella and Porzecanski 2015; Telles 2014; Telles and Lim 1998). Yet theoretically, the same processes are relevant to Europe, Asia and other regions of the world, even if those countries focus less explicitly on the concept of race (Ahmed, Feliciano, and Emigh 2007; Nagaraj et al. 2015; Perrin, Dal, and Poulain 2015; Song and Aspinall 2012).

Which dimension of race researchers use can significantly influence findings of racial inequality (Bratter and Gorman 2011; Noymer et al. 2011; Saperstein and Penner 2010, 2012; 
Telles 2014). Social surveys typically measure only one dimension of race, most frequently a circumscribed form of self-identification, leaving it to serve as a proxy for all of the others. Yet other dimensions of race may be theoretically more appropriate for studying specific social outcomes. At the same time, analyses of the ways that different dimensions of race influence the same outcomes can push scholars to rethink theoretical mechanisms that are taken largely for granted.

I begin by discussing the multiple dimensions of race and which ones may be more theoretically appropriate for examining which social outcomes. Next, I review literature that identifies inconsistencies between different dimensions and factors associated with those inconsistencies. This includes both statistical studies that include different race measures and the growing literature on multiracial people, which has advanced our theoretical understanding of how individuals can experience different dimensions of race. I also discuss studies showing that different dimensions of race produce different inequality estimates. Here, in addition to scholarship that explicitly addresses multiple dimensions of race, I argue that what have been treated as distinctive literatures focusing on specific dimensions should be understood within this broader framework. For example, I situate the substantial literature on colorism, or phenotype inequalities and discrimination, within a broader understanding of phenotype as one of several dimensions of race that influences the others but also produces its own axes of stratification. I also discuss the literature on genetic admixture inference, and while I challenge the view that current techniques for measuring genetic ancestry capture a particular dimension of race, I argue that this scholarship is enhanced by the inclusion of other race dimensions. Finally, I map the relationship between this body of scholarship and related literatures of racial fluidity and racial boundary change, and identify additional avenues that would advance this scholarship further.

\section{Mapping the Multiple Dimensions}

Figure 1 presents a typology of race dimensions reported in the literature, with some terms used to describe them, and outcomes they may be more appropriate for studying. This typology is not meant to be exhaustive but to provide a roadmap to the different components of race that scholars have been studying. One challenge for this scholarship is the variety of terms used for the same dimensions. In some cases, the same terms are used by different scholars to reference distinct dimensions (e.g. "racial identification"), prompting the need for greater theoretical clarity. All of these dimensions are fluid; they may vary over time and be influenced by a variety of contextual factors. However, fluidity within one dimension needs to be distinguished conceptually from differences across dimensions. To aid scholars conducting research in this area, the Multiple Components of Race Data Library (Bratter, Campbell, and Roth 2014) profiles social science surveys that include measures of multiple dimensions of race.

[Figure 1 about here] 
Racial Identity refers to a person's subjective self-identification. Importantly, it is not limited by a set of pre-determined options and does not represent a person's efforts to fit themselves into any given set of boxes. It is typically measured with an open-ended selfidentification question, and while it has more frequently been the focus of qualitative research, it could be captured through an open-ended question in survey research. This dimension might be most suited for studying outcomes that depend on an individual's internal self-identification process, such as political mobilization or voting patterns, residential decision-making, social network formation, or attitudes.

Racial Self-classification refers to the race that is checked on an official form or survey, such as a census or federal financial aid forms. It is typically measured with a closed-ended selfidentification question. Both racial self-classification and racial identity are forms of selfidentification, so it is a valid question whether these are actually theoretically distinct dimensions of the lived experience of race. On one hand, closed-ended questions are merely trying to measure racial identity and necessarily fail to capture all of its complexity due to their need to simplify response options for data analysis. However, the experience of having to fit oneself into boxes that do not represent how one identifies racially has become an important part of how many people experience the complexity of race. Several studies and artistic works highlight precisely this experience for groups such as Latinos and multiracial populations (Dowling 2014; Rockquemore and Brunsma 2002; Rodríguez 2000; Roth 2010; Scholler 2013). Race questions on national censuses are a particular case of racial self-classification, leading Bailey (2008) to refer to the answer people give specifically as their "Census race." Such questions, reflecting federal standards for data collection, represent a particular racial schema, a set of categories and way of thinking about race that reflects the nation's official classification system (Roth 2012). For example, in filling out the U.S. census, many people view themselves as providing the response that best fits the way they believe they are supposed to fit into America's official classifications, regardless of whether it matches their racial identity (Dowling 2014; Rodríguez 2000; Roth 2010). Other forms and surveys may have different variants of response options, but are similar in that individuals who see themselves falling between the boxes provided are forced to make a less-than-ideal choice.

Racial self-classification, as a proxy for racial identity, is frequently used to study a wide range of outcome measures, and when these two dimensions correspond (e.g. in the case of someone whose self-concept fits neatly within a society's official classification schema) this use is appropriate. When it is an inadequate proxy of racial identity, racial self-classification can provide some sense of how these groups see themselves fitting into official classifications (Rodríguez 2000). The distinction between racial self-classification and racial identity highlights that even in terms of self-identification, people may think about or express that identification differently in different contexts, and the nature of the question and options provided are aspects of that context. 
Observed Race is the race that others believe you to be. In social research, it is typically measured by the interviewer's classification of the individual. In a person's lived experience, it is assessed repeatedly and often silently in numerous, daily interactions and encounters. For individuals whose race is unambiguous, it may be assessed instantly and subconsciously; observers may not even be aware that they are silently cataloguing a person's race together with other pieces of information about them. For those whose race is more ambiguous, the process may take longer (Freeman et al. 2010) and be more conscious. A large literature in psychology examines how observers perceive the race of others (e.g., Pauker and Ambady 2009; Willadsen-Jensen and Ito 2006; see Roth 2015). These assessments influence how people are treated and form the basis of racial discrimination, including non-deliberate actions that nonetheless lead to socioeconomic inequities.

An important question for understanding how to interpret observed race is who is doing the observing. Characteristics of the observer influence how they perceive another individual's race (Feliciano In press; Harris 2002). An observer's knowledge of an individual with regard to some of the other dimensions of race may also influence their assessments. In one study, individuals who were previously surveyed about their ancestry but died before a follow-up study were identified by both a proxy - next of kin or nonrelatives who knew the individual - and by funeral directors. Only $20 \%$ of those who self-classified as Native American were classified as such by proxies, but none of them were classified as such by funeral directors (Hahn, Truman, and Barker 1996). Although even the proxies' assessments had low consistency with the individuals' self-classification, some likely had greater knowledge than the funeral directors of the individuals' racial identity or ancestry.

Similarly, the context of the observation matters for how a person's race is observed. Freeman and his co-authors (2011) find, in a series of images morphing photographs of Black and White individuals, low-status attire is associated with the person being perceived as Black and high-status attire is associated with being perceived as White. Furthermore, the influence of the attire grew as the race of the individual became more ambiguous, suggesting that people rely on non-physical features more when a person's race is not clear.

We can also think of two subtypes of the Observed Race dimension. Appearance-Based Observed Race is based solely on readily observable characteristics. This includes not only a person's phenotype but also visible status markers, clothing, hairstyle, and the context of the observation. Interaction-Based Observed Race is additionally shaped by information revealed through interaction, including a person's accent or language ability, name, knowledge of their family members, or comments about their background, status, or racial identity (Roth 2010). Observers may initially make an assessment of appearance-based observed race only to alter that assessment after interacting with them. Many Latinos describe being perceived as White or as Black until they open their mouths to speak, at which point their accent or use of Spanish leads an observer to reclassify them as Latino (Roth 2012). A person's name can also be used as a racial 
cue, with research showing that the same Asian-European multiracial faces are seen as looking significantly more European when associated with European names than with Asian names (Hilliar and Kemp 2008). Observers in different social roles rely on different sorts of information in their assessment of a person's race. Those most likely to engage in racial profiling or provide services, such as police officers, security guards, waiters, or salespeople, tend to rely on appearance-based observed race from their initial observations. But those with greater access to the resources associated with social mobility, such as employers, teachers, landlords, or lending agents, typically have greater interaction (Roth 2010). As a result, each type of observed race may be more suited to studying specific social outcomes.

The distinction between these subtypes remains greatly understudied. Studies of the classification of photographs or morphed images rely only on appearance, unlike most real interactions. A significant challenge for scholarship is that many surveys, as well as some qualitative studies, do not provide enough information to reveal whether the observed race measure reflects interviewers' assessments based on appearance or interactions. When and how the dimension is measured within a study can determine which one is captured. Observed race may be appearance-based when interviewers record a classification on their first observation of a respondent, but is interaction-based when recorded at the end of an interview. When the latter occurs in interviews that ask for racial self-identification, the interviewer's interaction-based assessment is likely to also be influenced by the individual's response.

A person can have many observed races - as many as there are observers and contexts in which they are observed. Although we typically capture this dimension of race once, from one interviewer, if we capture it at all, it can also be thought of as something specific to each moment and each act of observing.

Reflected Race refers to an individual's belief of how others classify them. It draws on the concept of reflected appraisals and the idea of the "looking-glass self" (Cooley 1902), which focuses on how an individual's racial identity is influenced by the perceptions of others. However, within the emerging literature, scholars consider reflected race a distinctive dimension of people's lived experience of race, one that may or may not influence their racial identity. In this way, it is useful for understanding the process of self-identification as well as other outcomes such as perceived discrimination.

However, most often reflected race - measured by questions such as "What race do most people think you are?" - is used as a proxy for observed race in self-administered or telephone surveys where interviewers cannot observe the person. The effectiveness of this proxy has never been studied. As noted above, one's observed race may differ based on the observers' characteristics. To the extent that the observed individual is aware of this, specifying the reference group doing the classifying may result in different responses. A mixed-race person with Black and White parents may believe that Whites usually view her as Black, but Blacks usually view her as 
mixed-race. The CDC's Behavioral Risk Factor Surveillance System (BRFSS) Measures of Racism Module asks respondents "How do other people in this country typically classify you?", which may be intended to capture how the mainstream society classifies the person, but how respondents interpret it could vary based on the extent of interactions they have with the mainstream society. Ideally, these questions would specify the reference group, whether it is mainstream society, the individual's own racial group, or specific minority groups (e.g. Blacks or Latinos).

Phenotype refers to aspects of a person's physical appearance that are socially understood as relevant to racial classification. This includes skin color as well as other features such as hair texture or color, nose shape, lip shape, and eye color. This is a dimension of race that varies, sometimes considerably, within racial categories. It affects most other dimensions of races but is not synonymous with any of them.

Much of the research on phenotype focuses on skin color, usually measured by interviewer classification with either a categorical question asking the interviewer to rate the person's skin color from light to dark or a color palette that interviewers memorize and apply to the respondent. Although more common in the past, few studies today use a spectrophotometer, an instrument that measures light reflectance off the skin, ${ }^{1}$ and measures of self-perceived skin color are fairly rare (Monk 2015). Thus the bulk of scholarship on skin color reflects someone else's perception of an individual's color. This may be appropriate for studies of color-based discrimination based on other people's perceptions. However, Monk (2015) shows that, compared to interviewer-rated skin color, self-reported skin color is actually a better predictor of internalized measures such as perceived discrimination, which predict key health outcomes among African-Americans. Future typologies of race dimensions may find it useful to distinguish self-reported and observed dimensions of phenotype, both skin color and other features, as data become available to explore these distinctions in greater depth.

Observed skin color, much like observed race, is influenced by the person doing the perceiving. Hill (2002) found that Black and White interviewers saw more color variation within their own race than in the other, such that White interviewers rated Black subjects' color as darker than did Black interviewers, and Black interviewers rated White subjects as lighter. Contextual cues also matter, and indeed the same kinds of social and interactional cues that distinguish interaction-based from appearance-based observed race - name, accent, language ability - may also influence an interviewer's rating of a person's skin color. An experimental study found that the inclusion of racially-coded names influenced how observers rated an image's skin color. Specifically, people rated the same face as darker when it was associated with a distinctively Hispanic name rather than a non-Hispanic name (Garcia and Abascal In press).

Phenotype is more complex than skin color alone, yet few surveys include measures of other features, and those that do typically only ask interviewers to record the respondent's hair 
color and eye color. Studies have found that nose, lips, and hair texture influence individuals' classifications, although skin color is the primary characteristic used to classify a person's race (Feliciano In press). Few studies consider how these other phenotypic features influence perceptions of skin color, observed race, or socioeconomic outcomes (cf Gravlee 2005). One study found that some Latinos rated their own skin color darker than a White American observer rated their color because they had African or Indigenous facial features; they viewed their non-European nose, lips or hair texture as darkening their overall color, while the American observed focused only on skin tone (Roth 2012).

Racial Ancestry is a dimension of race that influences other dimensions, such as racial identity and observed race. This is particularly true in the United States, where racial ancestry was used as the basis for determining who was Black for much of the nation's history (Davis 1991), as well as what fraction of Indigenous ancestry was needed to be considered Native American (Snipp 1989). In assessing what another person is (or making a judgment about appearance-based observed race), observers often rely on phenotype, but do so because such physical differences are thought to reveal an ancestral lineage (Smedley and Smedley 2012). In fact, because racial classification depends not just on phenotype but also on ancestry in North America, many view race as "a supra-individual, social-relational phenomenon, not as a subjective individual property" (Brubaker 2015:22), where someone cannot take on a race from which they have no ancestry. The widespread public rejection of the Black identity claimed by Rachel Dolezal, the NAACP chapter president who was revealed to be of European descent, is a case in point. In other societies, racial ancestry is less important and simply living the life of a group member is sufficient for inclusion (Wimmer 2008).

Although we can think of racial ancestry as the compiled racial groups of one's ancestors, most people are unaware of all of the racial ancestry they have. Knowledge of family trees may only go back a few generations, and in some cases, racial ancestries were buried when relatives passed as members of different races to pursue greater opportunities or avoid social exclusion. In practice, what most people think of as their racial ancestry is their Known Ancestry - what a person believes her racial ancestry to be based on family history. Survey questions on ancestry, such as the U.S. Census's open-ended self-report question, attempt to capture known ancestry, although people's responses may not be comprehensive, as some forget parts of their ancestry or simplify what they report (Waters 1990).

The ancestry question was placed on the U.S. Census and other surveys to study immigrant integration and ethnic assimilation. But Gullickson (In press) argues that these write-in ancestry responses indicate an essentialized identity that is often related to but distinct from racial selfidentification. Analyzing ancestry and self-classification of race or Hispanic origin together can indicate how people's self-classifications draw upon some components of their racial ancestry and not others. For example, identifying multiracial individuals by ancestry and examining who also identifies as multiracial on survey race questions can provide new estimates of the multiracial 
population and illuminate who chooses a multiracial identity (Gullickson and Morning 2011). Examining the characteristics of people who report a Latino ancestry but do not identify as Latino or Hispanic on the census Hispanicity question can also reveal what factors are associated with the loss of a Latino identity (Alba and Islam 2009; Duncan and Trejo 2011; Emeka and Vallejo 2011). In these ways, racial ancestry is appropriate for studying social status and social closure, as well as assimilation and racial boundary crossing.

Even known ancestry is fluid as what people know about their racial ancestry can change over time. Through genealogical research, people may learn of ancestors pruned from family trees or who passed across racial lines (Broyard 2008; Williams 1996). Those who were adopted and later connect with their biological families may also learn new information about their racial ancestry. While this dimension of race is typically less fluid than others, some people do make discoveries that can influence other dimensions, particularly racial identity.

One way of discovering new information about racial ancestry is through genetic ancestry testing. Nearly three million tests have been sold by approximately 40 direct-to-consumer companies in a little over a decade (Roth and Lyon In press). These tests purport to tell people about their geographic ancestral origins by analyzing genetic variation that occurred during worldwide human migrations. We can think of this information as a Genetic Ancestry dimension, which may include racial ancestries that were previously unknown to an individual from her family history or genealogical research. Critics point out several limitations of these tests, including that analyses are restricted by the other individuals within a company's database and that the probabilistic nature of the findings is not properly qualified (Bolnick et al. 2007; Duster 2011; Royal et al. 2010). In some cases, test-takers can confirm new ancestry information by connecting with other test-takers whose DNA suggests relatedness. While many test-takers understand the tests' limitations, others misinterpret what the tests can tell them about ancestry (Roth and Lyon In press). Whether or not these interpretations are supported by the evidence, the information from test-takers' genetic ancestry can inform what they report as their known ancestry when they accept the results.

Increasingly, genetic measures of racial ancestry are used in population-level research and health studies (e.g., Atzmon et al. 2010; Bauchet et al. 2007; Marcus et al. 2010; Perez et al. 2013). There are several problems with how genetic ancestry is measured and interpreted by both genetic ancestry test-takers and population geneticists, as I discuss further below. Yet as new technologies attempt to provide information about a person's deep ancestry beyond what is known in a family's collective memory, genetic ancestry may increasingly influence both individuals' lives and popular discourse about what race is.

Below I review the major themes in recent scholarship on the multiple dimensions of race. I focus on work that delineates the inconsistencies across dimensions of race and the factors associated with them, the relationship between different dimensions, and how using different 
dimensions of race influences estimates of inequalities and what this implies for analytical approaches.

\section{Major Themes in the Literature}

\section{Inconsistencies across Dimensions}

One theme in this scholarship is exploring the inconsistencies across dimensions of race and its associated factors, particularly the inconsistencies between racial self-classification and observed race. For example, several U.S. studies in the health fields examined inconsistencies between individuals' self-reports and the observations of others in the form of medical records, interviewer classifications, or death certificates (Hahn et al. 1996; Kressin et al. 2003; West et al. 2005). ${ }^{2}$ These studies found the highest rates of consistency among self-reported Whites (91-98\%) and self-reported Blacks (90-99\%), and typically moderate-to-high rates among Asians (76-95\%) and Hispanics (64-83\%), but low rates of consistency for Native Americans (0-23\%). In a comparison of racial self-classification in the 2000 U.S. Census and observed race in the 2000 General Social Survey, Smith (2001) similarly found 97-98 percent agreement for Blacks and Whites but only 58\% agreement for other races. Saperstein (2006) also found that inconsistencies between self-classification and observed race, while small overall, were rapidly growing - with a 55\% increase between 1996 and 2000.

However, most of these studies include only cases where observers marked a race for the individual. When the observer was allowed to mark "unsure" or "race unknown," many did so, suggesting even lower levels of consistency. For instance, Kressin et al. (2003), who reported 98\% consistency for Whites and 92\% for African Americans between observed race and selfclassification, found those levels dropped to $62 \%$ and $61 \%$ respectively when they included observers' reports of "race unknown" (see also Boehmer et al. 2002).

In these studies, it is difficult to know whether the observer - typically an interviewer or health administrator - is recording observed race based only on appearance or on interactions as well. In an important new study, Rastogi, Liebler and Noon (In press) shed light on the process of interaction-based observed race by examining the racial classifications made by proxies, people outside the household who know the target individual. Drawing on a unique dataset of individually-linked records from the full 2000 and 2010 U.S. censuses, they leverage 3.7 million cases with both a proxy report, usually from a neighbor, and a report for the same individual by someone within the household. They find high consistency between the household reports and proxy reports for the nation's largest groups: $98 \%$ of Whites, 94\% of Blacks, $88 \%$ of Asians, and $86 \%$ of Hispanics. However, proxy reports matched household reports for only $62 \%$ of Native Americans, $62 \%$ of Pacific Islanders, and 8-36\% of multiracial people, depending on the mix of races reported. Unfortunately the data cannot reveal who makes the household report - or whether 
this study reflects consistency between interaction-based observed race and racial selfclassification (if the household report comes from the individual herself) or the fluidity in interaction-based observed race that occurs when there are different observers, even ones who know the individual.

This scholarship has also examined the factors associated with inconsistencies in selfclassification and observed race. It understandably finds greater consistency under conditions that would improve the observers' knowledge of the individual. We would expect observed race that is based on interaction to match the way a person self-identifies more often than that based only on appearance, and these studies suggest that greater interaction leads to greater consistency (Kressin et al. 2003; Rastogi et al. In press). Observers who have less knowledge of an individual often rely on social cues to determine what that person's race might be. Many of these are associated with stereotypes or assumptions based on social status. For instance, proxies may rely on positive or negative stereotypes about groups' financial standing in reporting an individual's race. Homeownership is associated with higher odds of consistent classification for Asians, but lower odds for Native Americans, while the odds of consistent classification were higher for many minorities in areas with more people using public assistance. (Rastogi et al. In press). Racial stereotypes about health and group behavior can also influence observers' classifications and their inconsistency with proxy reports by relatives; on death certificates, medical examiners were more likely to classify someone as Native American who had died of cirrhosis, and to classify someone as Black whose cause of death was homicide, with the race reported by the person's next of kin held constant (Noymer et al. 2011).

Observers also rely on contextual cues and racial classification norms when guessing the race of others. Rastogi et al. (In press) found that proxy classifications were more likely to match household reports if the person was living in an area where many others report the same race, suggesting that observers rely on the racial composition of the area to guide their assessments. However, for people identified by their household as Black-White, proxy reports were more likely to be inconsistent if the area had a high number of Blacks. In general, Black-White multiracial people were more often observed as Black than as other races, reflecting social norms of hypodescent. Proxies also tended to report children as multiple-race and adults as single race, which may reflect societal ideas that younger people are more likely to view themselves as multiracial and/or a greater tendency to see young people with their parents and to draw upon this information about racial ancestry in reporting race.

\section{The Consequences of Inconsistencies}

While much of the research on inconsistencies across dimensions of race points toward the implications of using different measures to study inequality (see below), some studies examine the impact of the inconsistency itself on the individuals who experience it, showing that being perceived differently from how one classifies oneself can have negative psychological and health 
consequences. Campbell and Troyer (2007) examine indicators of psychological distress among those who classify themselves as Native American but are perceived as another race by an observer. Relative to those with consistent classifications, those classified as a different race have an increased likelihood of considering or attempting suicide and of fatalistically believing that they will die before the age of 35 . The authors argue that this mismatch in observed race and selfclassification increases stress and leads to negative mental health outcomes by invalidating one's self-image and identity, threatening social status, and de-legitimizing claims for membership in one's community. ${ }^{3}$

Other studies consider the impact of inconsistencies between a person's racial selfclassification and reflected race, arguing that a person's perception of being routinely viewed as a different race is more important for emotional or physical responses than a single instance of being observed differently by an outsider, of which she may not even be aware. Applying a status perspective, Stepanikova (2010) shows that people who believe they are classified as a lower status race than the one they report for themselves have significantly higher odds of reporting physical and emotional symptoms as a result of how they were treated based on their race. Yet those who believe they are classified as a higher status race do not experience symptoms that are significantly different from people who believe their race is validated by others.

Vargas (2014) finds that individuals who self-classify as White but do not believe that others view them this way are more likely to express similar or amplified notions of colorblindness in order to legitimate their membership in the White group from which they feel marginalized. Meanwhile, people who claim a race that they believe is contested by others generally experience lower levels of racial group closeness and racial identity salience, which may lead to a thinning of racial identity when self-classification is inconsistent with reflected race (Vargas and Stainback In press). In Canada, people whose self-classification did not match their reflected race were significantly more likely to report suffering from high blood pressure and hypertension, and poorer self-rated mental health and overall health than those not experiencing a mismatch (Veenstra 2011). Inconsistency between racial self-classification and both observed and reflected race is associated with a number of negative physical and emotional outcomes (but see Song and Aspinall 2012).

\section{The Relationship between Dimensions}

Another theme in the literature is how one dimension of race influences another. Some work considers how phenotype, particularly skin color, influences racial self-classification, for example. Latinos with darker-skin are more likely to classify their race as Black or as Hispanic, and less likely to self-classify as White, compared to those with lighter skin (Golash-Boza and Darity 2008). Similarly, qualitative research shows that phenotype influences the racial identity of multiracial individuals (Rockquemore and Brunsma 2002; Song and Aspinall 2012). The influence of skin color on self-classification varies between nations, however. In Latin America, skin color 
has a strong effect on who self-classifies as Black in Panama but a weak effect in the Dominican Republic, with Colombia and Brazil in between (Telles and Paschel 2014).

The concept of reflected appraisals implicitly examines the relationship between different dimensions of race - how reflected race influences racial identity. Although the term "reflected race" derives from this theory, it is not the same as a reflected appraisal, as not everyone conforms their racial identity to the way they believe others view them (Vargas 2015; Vargas and Stainback In press). Nonetheless, Khanna (2004, 2010) shows precisely how Black-White and Asian-White multiracial people's identities are influenced by how they believe they are classified, a belief which is itself closely tied to their phenotype.

Feliciano (In press) analyzes how individuals' phenotype influences their observed race, as well as inconsistencies between observed and self-classified race. Using photos that are uploaded to match.com and are associated with would-be daters' own classifications, she considers how those photos are racially classified by a number of different observers. She finds that observers tend to place individuals into monoracial groups, using skin tone as their primary guide. Notably, while light skin is associated with a White designation, and dark skin with a Black designation, medium skin is associated with a Latino designation, suggesting the extent to which observers have come to see Latinos as a racial group that is both phenotypically and categorically in-between Black and White.

In ongoing work, I am investigating how genetic ancestry influences racial identity and self-classification by examining people's responses to genetic ancestry tests. Many people who take these tests say that they influence their racial or ethnic identity (Roth and Lyon In press). But test results indicating new ancestries do not automatically transform existing identities if the individual is not receptive to the idea of that particular transformation, such as by viewing those new ancestries positively, believing that they fit their personality or appearance, or seeing them as offering closure to long-held identity questions. Those who are less receptive tend to reject the results and do not incorporate them into their sense of self. Despite popular beliefs that people tend to privilege scientific or genetic information as more unbiased and factual, this work finds that genetic ancestry information has only a moderate impact on racial identity, well below the impact of other dimensions such as observed race, reflected race, or phenotype.

\section{Different Dimensions, Different Outcomes}

Among the important findings from this literature is that using measures of different dimensions of race influences findings on inequality. We have seen this with respect to racial inequalities in health, criminal justice, and socioeconomic outcomes. However, the data are not always consistent with regard to which measure reveals the greatest racial disparities in outcomes.

In the health fields, some find that using observed race rather than self-classification can depress estimates of health problems among Native Americans. Many people who self-classify as 
Native American are classified differently by health professionals - most often as White. Using observed race from administrative records rather than self-identification tends to lower estimates of cancer incidence and injury among Native Americans (Frost, Taylor, and Fries 1992; Sugarman et al. 1993). However, using self-classification may also obscure important aspects of how race contributes to health inequalities, particularly if only one race response is allowed. Many multiracial individuals with Native American and White ancestry choose White when asked to select a single race, despite health profiles that are more disadvantaged than Whites and more similar to Native Americans overall (Bratter and Gorman 2011).

In studies of health care provision, we might expect observed race to more closely mirror experiences of discrimination in service provision. Yet what little evidence exists is mixed. Observed race reveals greater inequalities in women's health screening than does selfclassification; being seen as White is associated with lower rates of pap smear screenings than selfidentifying as White (Saperstein 2012). A study of dental outpatients examined the odds of having a root canal treatment rather than tooth extraction using self-classified and observed race, and found that African-Americans were less likely and Asians more likely than Whites to obtain root canal therapy regardless of the race dimension used. But when using self-classification, Hispanics were significantly less likely than Whites to obtain a root canal rather than tooth extraction, while their odds of obtaining a root canal were not significantly different from Whites when using observed race (Boehmer et al. 2002).

Focusing on criminal justice outcomes and potential discrimination that can occur at various levels, observed race appears to be more influential than self-classification. One study found that the odds of young people being arrested are significantly higher if they are perceived as Black by others, even if they do not self-classify as Black (Penner and Saperstein 2015).

With regard to socioeconomic outcomes, Saperstein (2006) found that even though levels of inconsistency between observed race and self-classification were small in the population overall, they were significant enough to affect estimates of family income; she found that selfclassification revealed greater race gaps in family income than observed race. Yet in another study, observed race revealed greater inequalities in women's family income than did racial selfclassification. Being seen as White by others was associated with higher family income than selfidentifying as White (Saperstein 2012). This pointed toward the same mechanisms as an earlier study in Brazil that found significantly higher rates of racial income inequality based on observed race than on self-classification. While the gap between Browns (pardos) and Blacks varied little based on the race measure, there were significant differences in the income gaps between Whites and Browns. Using observed race, Whites earned 26\% more than Browns, but only $17 \%$ more than Browns using self-classification (Telles and Lim 1998).

In a cross-national study comparing Brazil, Colombia, Mexico, and Peru, Telles (2014) found evidence of stratification by skin color, particularly in education and occupational status, 
and argued that self-identification is less reliable for assessing ethnoracial inequality than classification by others and, especially, external evaluation of skin color. Yet extending this examination to 19 countries across Latin America and the U.S., Bailey, Fialho and Penner (In press) found considerable variation throughout the region in how skin color and racial selfclassification mapped onto social inequality in household incomes and how each one was mediated by social class. They argue that neither dimension is unilaterally better, but must be examined at the country level.

Thus, while the dimension of race that is used affects many estimates of inequality, it is not always clear which one will best explain the data. One way to approach the dilemma of which measure to use is to follow the theoretical expectations for the particular outcome being studied and the mechanisms expected to influence it. Thus a study focusing particularly on discrimination in the housing market might select observed race, while one focusing on residential decisionmaking might select racial identity (or its common proxy, self-classification). However, researchers often want to be able to tease apart both of these mechanisms in explaining racial differences in outcomes (suburban residence, for example). In this case, quantitative researchers should include both dimensions in their models. Indeed, Saperstein, Kizer and Penner (In press) detail different analytical strategies for doing so, ranging from testing specific hypotheses about mechanisms to exploratory analyses. Those that want to explore which dimensions matter most often face challenges in explaining the patterns they find; indeed, an important avenue for future research is to complement the more exploratory studies with theory building and advanced work testing emerging hypotheses.

\section{Other Literatures that Capture Multidimensionality}

While a growing scholarship explicitly addresses the multiple dimensions of race, other fairly self-contained literatures can now be situated within a larger framework of multidimensionality, for example research on colorism or phenotype inequalities and discrimination. Skin color produces social stratification along numerous social outcomes that is distinct from stratification on the basis of racial categorization. Indeed, scholars have found phenotype inequalities within U.S. racial groups where lighter or more European phenotypes are associated with better outcomes in income and wealth (Frank, Akresh, and Lu 2010; Kreisman and Rangel 2014), educational attainment (Branigan et al. 2013; Monk 2014), residential segregation (South, Crowder, and Chavez 2005), health and healthcare (Baker et al. 2010; Codina and Montalvo 1994; Gravlee, Dressler, and Bernard 2005), school suspension (Hannon, DeFina, and Bruch 2013), arrest rates (White 2015), and prison sentence length and time served (Viglione, Hannon, and DeFina 2011). Color inequalities also persist outside of the U.S., with much of the research focusing on Latin America (Bailey et al. In press; Telles 2004, 2014). 
This literature fits within a multidimensional framework because an awareness of racial categories is implicit. Scholars typically restrict their analyses to one racial group, usually selfidentified; in doing so, they reveal the heterogeneity within racial classifications. The overriding point of the colorism literature is the variation of experience within categories as well as between them. This is effectively the same point as showing that, even among people who self-identify the same way, perception by others affects their experience of race and vice versa. All of this scholarship works toward the same goal of illustrating that the experience of race is much more complex than a single, monolithic label. The colorism literature simply does so, most often, while holding other dimensions of race constant.

Studies that examine whether color or racial categorization matter more for understanding unequal opportunities and outcomes typically find complex interactions between them (Bailey et al. In press; Ronquillo et al. 2007; Telles 2004, 2014). Thus while some argue that one should be used in lieu of the other (Banton 2012), the question is not whether color or racial classification (by oneself or others) tells us more about inequality, but how they both reveal the way that inequalities unfold along many simultaneous dimensions that are all related to how people experience racialized difference.

Another body of literature that captures the multidimensionality of race - albeit sometimes unbeknownst to the researchers - is genetic admixture studies in population genetics and health research. This research relies on the analysis of "ancestry informative markers" (AIMS), genetic variants whose frequency differs between continental groups. AIMS are identified from "unadmixed" populations - samples collected from contemporary West Africans, Europeans, or Native Americans, for instance, who are geographically isolated and report homogeneous ancestry. Researchers use computer estimation to identify genetic variants that differ across populations being analyzed.

Rather than determining racial ancestry by purely genetic means, this type of analysis relies on existing social understandings of what these populations are to identify the genetic markers that differ most between them. Without an a priori sense of who is West African, European, Native American, and so on, and including comparison samples from groups which are so designated, the analysis software would not be able to divide samples into discrete categories because most human traits are clinal, existing along a gradient of continuous change (Graves 2013). In a study using the three populations mentioned above, researchers have to tell the computer to look for AIMS that will divide the sample into three populations, but they would get different results if they asked it to be divided into four, eight, or twenty populations. In other words, it is because these studies set out to look for discrete, categorical differences that map onto existing social ideas about what the populations should be that they find them, all the while suggesting that such differences are natural and free of social influence. 
Genetic measures of ancestry, then, are not objectively natural but rather are affected by other dimensions of race. We should not be surprised that they overlap with other dimensions such as racial self-classification (Guo et al. 2014) because both reflect the same underlying social categorizations. But what do these measures actually represent and are they analytically useful? When researchers attempt to measure "genetic ancestry," what they are actually capturing is a probability that the individual and someone in a particular, contemporary racial group share a common ancestor going back many more generations than most family trees extend. But because of how populations change, it is not clear that the common ancestor resembles our contemporary notions of what a "European" or a "Native American" is (Duster 2011). These measures are capturing an aspect of biological descent, but not one that informs our understanding of racial ancestry in an analytically meaningful way.

And yet here is another situation where the researchers' attempts to account for the multidimensionality of race enhances our understanding of the mechanisms driving racial inequalities. Several studies that include both measures have found that racial self-classification explains health inequalities better than genetic ancestry. In their study of southeastern Puerto Ricans, Gravlee, Non, and Mulligan (2009) include both measures of observed race and genetic ancestry (ancestry informative markers indicating African ancestry) and discover that observed race (in interaction with socio-economic status), but not genetic ancestry is associated with blood pressure. Perez et al. (2013) include measures of racial self-classification and genetic ancestry (genome-wide European ancestry) to find that self-classification as African-American, but not European genetic ancestry, is associated with lower rates of atrial fibrillation. Similarly, in a study of European-Americans and African-Americans, genetic ancestry does not predict cardiovascular disease better than racial self-classification (Halder et al. 2012). These findings support the arguments of evolutionary biologists and others that the vast majority of racial health disparities are explained by environmental rather than genetic causes (Graves 2013). Thus, it is particularly important for health researchers using these biosocial measures of genetic ancestry to include other dimensions of race such as self-classification or observed race, to avoid misattributions of racial health inequalities to genetic causes. ${ }^{4}$

\section{Situating and Advancing the Multidimensionality of Race}

In this final section, I map the relationship between the multidimensionality of race and other processes that contribute to the complexity of how people experience race - namely, racial fluidity and racial boundary change. These are also lively areas of study, and it enhances scholarship in general to have greater theoretical clarity in which processes are being explored and how they relate to and differ from the others. I also suggest where further research can help us better understand these relationships and the multidimensionality of race on its own. 
Racial fluidity refers to fluctuation in one dimension of race as opposed to inconsistency across different dimensions. It is useful to further distinguish between temporal fluidity, changes over time within the same context, and contextual fluidity, changes across contexts within a fairly limited period of time. Temporal fluidity is of particular interest to psychologists who study racial identity development, particularly during adolescence and young adulthood. But we also see it among adults in longitudinal studies, assuming that the question formats and contexts do not change much from one survey to another (Doyle and Kao 2007; Liebler et al. 2014; Saperstein and Penner 2012). Contextual fluidity includes the different social settings in which a question is asked, such as asking an adolescent to racially self-classify at home and at school (Harris and Sim 2002). It is also what is captured by changes to the questions themselves and by observers' characteristics. When we talk about observed race, the specific observer being referenced is part of the context.

As discussed above, each dimension of race is fluid, and this can lead to a lack of clarity in the broader literature between fluidity within one dimension and inconsistency between different dimensions. This distinction is shown in the top-left of Figure 2. Fluidity and multidimensionality are sometimes jointly referred to as "inconsistency," which serves to highlight that race is not static, but does not help us understand the particular nature of its dynamism.

[Figure 2 about here]

Research on the multiple dimensions of race and on racial fluidity both point to micro-level social processes. Racial boundary change occurs at both the micro- and macro-levels, and the former two processes alone do not determine macro-level boundary change (Wimmer 2008), although they may contribute to it. The micro-level processes we observe when we measure racial fluidity or an inconsistency between racial identity and observed race, for instance, generally occur on a relatively short time frame compared to that of macro-level boundary processes (see Figure 2). These micro-level processes speak to the character of the boundary, particularly whether it is bright or blurred (Alba 2005). Large inconsistencies between race dimensions or substantial fluidity in one dimension both point to a lack of agreement over who falls where, which suggest a blurred boundary. But without looking at whether these inconsistencies or fluidity occur repeatedly over long periods of time, this does not necessarily reveal processes of boundary change. A boundary maybe be blurred and stably so; this does not mean that it is blurring, which suggests change in the nature of the boundary over that longer time frame.

When thinking about how racial boundaries change over time, the issue of the multidimensionality of race is quite central. Macro-level boundary change is arguably most related to observed race - how people are classified by others, and particularly by the most privileged groups. Large numbers of Latinos may classify themselves as White on the census, but it is only when the dominant White group comes to view them this way that we think of the White racial boundary as having expanded. Unfortunately, we do not have good public opinion data over time on how immigrant or ethnic groups are perceived racially. Researchers can consider these shifts 
historically by examining the public discourse of dominant groups, but the particular nature of how people were racially classified is subject to debate (Fox and Guglielmo 2012).

To advance scholarship on the multiple dimensions of race, and perhaps in the long term on racial boundary change, more work is needed on how dominant groups perceive the race of others-both particular individuals shown in a variety of social contexts and entire ethnic or immigrant groups. Experimental studies that can vary aspects of the context in which individuals are shown (e.g., Freeman et al. 2011) are a promising route to understanding more about how racial attribution is made. Focusing on both individuals and groups would help to distinguish between different boundary processes, such as the repositioning of certain types of individuals through boundary crossing compared to a boundary expanding to incorporate new groups (Wimmer 2008).

There are a number of other promising avenues for future work on the multiple dimensions of race. There is still considerable work to be done in establishing which dimensions of race matter most in explaining different types of outcomes. Some studies point in different directions, and there is not yet enough research to allow a meta-analysis across samples. At present, we can say which dimensions we expect theoretically to be most appropriate, as I have attempted to do in Figure 1. But we still need empirical work to test whether those hypotheses are supported, and to develop and test additional theories when they are not.

Few studies test the validity of using one dimension of race as a proxy for another. Often proxies are used because of the difficulty of measuring particular dimensions with particular research designs (i.e., racial identity in survey research, observed race in self-completion modes of survey research). Future research should determine how estimates of racial inequalities are affected by using perceived race as a proxy for observed race, or racial-classification as a proxy for racial identity.

Of course, future research in these areas depends on having more data sets that measure multiple dimensions of race, which at present are few in number (Bratter et al. 2014). Those who design and implement surveys often need to be convinced of the value of adding questions that capture these multiple dimensions (Saperstein 2013). This is particularly true outside of the United States and Latin America, the regions that have been the focus of most of this research. Although the theoretical distinctions between different dimensions of race are relevant in many parts of the world, more empirical research is needed in Europe, Asia, Australia, and the Middle East, to understand how they affect people's lived experience. In the United States, the number of people who experience race as a number of conflicting dimensions will likely grow, making it more important to understand how the multidimensionality of race affects research estimates, statistics, and the experience of a growing number of people. Yet in all societies, understanding the diverse dimensions of race shows how racial inequalities are constructed in multiple ways - from within and without, by aspects of our experiences, our appearance, our interactions, and our family history, and by no single one of these on its own. 


\footnotetext{
${ }^{1}$ Although sometimes presented providing an objective measure of skin color, spectrophotometer readings are influenced by background lighting and the part of the body that is measured, including how tanned that body part is at the moment of the reading (Garcia and Abascal In press).

${ }^{2}$ Some of these studies attempted to study the "validity" of race data in vital statistics or medical records without recognizing that the observed classifications represented a different dimension of race than the self-classification data used to verify it (e.g., Baumeister et al. 2000).

${ }^{3}$ Campbell and Troyer (2007) focus on Native Americans precisely because of the typically high levels of inconsistency between their self-classification and observed race. Native Americans generally reveal higher levels of racial ambiguity compared to other U.S. groups.

${ }^{4}$ Or alternatively, genetic contributions to health can be analyzed through a panel of gene sequences (single-nucleotide polymorphisms) that are not associated with efforts to genetically measure continental or racial ancestry.
}

\section{$\underline{\text { References }}$}

Ahmed, Patricia, Cynthia Feliciano, and Rebecca Jean Emigh. 2007. "Internal and External Ethnic Assessments in Eastern Europe.” Social Forces 86(1):231-55.

Alba, Richard. 2005. "Bright vs. Blurred Boundaries: Second-Generation Assimilation and Exclusion in France, Germany, and the United States." Ethnic and Racial Studies 28(1):20-49.

Alba, Richard and Tariqul Islam. 2009. "The Case of the Disappearing Mexican Americans: An Ethnic-Identity Mystery." Population Research and Policy Review 28(2):109-21.

Atzmon, Gil et al. 2010. “Abraham's Children in the Genome Era: Major Jewish Diaspora Populations Comprise Distinct Genetic Clusters with Shared Middle Eastern Ancestry." The American Journal of Human Genetics 86(6):850-59.

Bailey, Stanley R. 2008. "Unmixing for Race Making in Brazil.” American Journal of Sociology 114(3):577-614.

Bailey, Stanley R., Fabrício M. Fialho, and Andrew M. Penner. In press. "Interrogating Race: Color, Racial Categories, and Class across the Americas." American Behavioral Scientist.

Baker, Rachel B., Jamison D. Fargo, Donna Shambley-Ebron, and Marilyn S. Sommers. 2010. "A Source of Healthcare Disparity: Race, Skin Color, and Injuries after Rape among Adolescents and Young Adults." Journal of Forensic Nursing 6(3):144-50. 
Banton, Michael. 2012. "The Colour Line and the Colour Scale in the Twentieth Century." Ethnic and Racial Studies 35(7):1109-31.

Bauchet, Marc et al. 2007. "Measuring European Population Stratification with Microarray Genotype Data." American Journal of Human Genetics 80(5):948-56.

Baumeister, L., K. Marchi, M. Pearl, R. Williams, and P. Braveman. 2000. "The Validity of Information on 'Race' and 'Hispanic Ethnicity' in California Birth Certificate Data." Health Services Research 35(4):869-83.

Boehmer, Ulrike et al. 2002. "Self-Reported vs. Administrative Race/Ethnicity Data and Study Results." American Journal of Public Health 92:1471-73.

Bolnick, Deborah A. et al. 2007. "The Science and Business of Genetic Ancestry Testing." Science 318:399-400.

Bolnick, Deborah A. 2008. "Individual Ancestry Inference and the Reification of Race as a Biological Phenomenon." Pp. 70-88 in Revisiting race in a genomic age, Rutgers studies in medical anthropology, edited by B. A. Koenig, S. S.-J. Lee, and S. S. Richardson. New Brunswick, N.J: Rutgers University Press.

Branigan, Amelia R. et al. 2013. "Skin Color, Sex, and Educational Attainment in the Post-Civil Rights Era.” Social Science Research 42(6):1659-74.

Bratter, Jenifer L., Mary E. Campbell, and Wendy D. Roth. 2014. "Multiple Components of Race Data Library [Online Database].” Retrieved (http://kinder.rice.edu/racedatasets/).

Bratter, Jenifer L. and Bridget K. Gorman. 2011. "Does Multiracial Matter? A Study of Racial Disparities in Self-Rated Health." Demography 48:127-52.

Broyard, Bliss. 2008. One Drop: My Father's Hidden Life: A Story of Race and Family Secrets. 1st Back Bay pbk. ed. New York: Back Bay Books.

Brubaker, Rogers. 2015. "The Dolezal Affair: Race, Gender, and the Micropolitics of Identity." Ethnic and Racial Studies 0(0):1-35.

Cabella, Wanda and Rafael Porzecanski. 2015. "The Growth of Ethnic Minorities in Uruguay: Ethnic Renewal or Measurement Problems?" Pp. 175-90 in Social Statistics and Ethnic Diversity: Cross-National Perspectives in Classifications and Identity Politics, IMISCOE Research Series, edited by P. Simon, V. Piché, and A. A. Gagnon. New York: Springer International Publishing.

Campbell, Mary E. and Lisa Troyer. 2007. "The Implications of Racial Misclassification by Observers." American Sociological Review 72(5):750-65.

Codina, G. Edward and Frank F. Montalvo. 1994. "Chicano Phenotype and Depression." Hispanic Journal of Behavioral Sciences 16:296-306. 
Cooley, Charles Horton. 1902. Human Nature and the Social Order. New York: Charles Scribner's Sons.

Davis, F. James. 1991. Who Is Black? One Nation's Definition. University Park, PA: Pennsylvania State University Press.

Dowling, Julie A. 2014. Mexican Americans and the Question of Race. University of Texas Press.

Doyle, Jamie Mihoko and Grace Kao. 2007. “Are Racial Identities of Multiracials Stable? Changing Self-Identification Among Single and Multiple Race Individuals." Social psychology quarterly 70(4):405-23.

Duncan, Brian and Stephen J. Trejo. 2011. "Intermarriage and the International Transmission of Ethnic Identity and Human Capital for Mexican Americans." Journal of Labor Economics 29(2):195-227.

Duster, Troy. 2011. “Ancestry Testing and DNA: Uses, Limits, and Caveat Emptor.” Pp. 99-115 in Race and the genetic revolution: science, myth, and culture, edited by S. Krimsky and K. Sloan. New York: Columbia University Press.

Emeka, Amon and Jody Agius Vallejo. 2011. "Non-Hispanics with Latin American Ancestry: Assimilation, Race, and Identity among Latin American Descendants in the US." Social Science Research 40(6):1547-63.

Feliciano, Cynthia. In press. "Shades of Race: How Phenotype and Observer Characteristics Shape Racial Classification." American Behavioral Scientist.

Fox, Cybelle and Thomas A. Guglielmo. 2012. "Defining America's Racial Boundaries: Blacks, Mexicans, and European Immigrants, 1890-1945." American Journal of Sociology 118(2):327-79.

Frank, Reanne, Ilana Redstone Akresh, and Bo Lu. 2010. "Latino Immigrants and the U.S. Racial Order How and Where Do They Fit In?" American Sociological Review 75(3):378-401.

Freeman, Jonathan B., Kristin Pauker, Evan P. Apfelbaum, and Nalini Ambady. 2010. "Continuous Dynamics in the Real-Time Perception of Race." Journal of Experimental Social Psychology 46(1):179-85.

Freeman, Jonathan B., Andrew M. Penner, Aliya Saperstein, Matthias Scheutz, and Nalini Ambady. 2011. "Looking the Part: Social Status Cues Shape Race Perception." PLoS ONE 6(9):e25107.

Frost, Floyd, Victoria Taylor, and Elizabeth Fries. 1992. "Racial Misclassification of Native Americans in a Surveillance, Epidemiology, and End Results Cancer Registry." Journal of the National Cancer Institute 84(12):957-62. 
Garcia, Denia and Maria Abascal. In press. "Colored Perceptions: Racially Distinctive Names and Assessments of Skin Color." American Behavioral Scientist.

Golash-Boza, Tanya and William A. Darity. 2008. "Latino Racial Choices: The Effects of Skin Colour and Discrimination on Latinos' and Latinas' Racial Self-Identifications." Ethnic and Racial Studies 31:899-934.

Graves, Joseph L. 2013. 'Looking at the World through 'Race'-Colored Glasses: The Fallacy of Ascertainment Bias in Biomedical Research and Practice." Pp. 39-52 in Mapping "Race": Critical Approaches to Health Disparities Research, edited by L. E. Gomez and N. Lopez. New Brunswick, N.J: Rutgers University Press.

Gravlee, Clarence C. 2005. "Ethnic Classification in Southeastern Puerto Rico: The Cultural Model of 'Color."' Social Forces 83(3):949-70.

Gravlee, Clarence C., William W. Dressler, and H. Russell Bernard. 2005. "Skin Color, Social Classification, and Blood Pressure in Southeastern Puerto Rico.” American Journal of Public Health 95(12):2191-97.

Gravlee, Clarence C., Amy L. Non, and Connie J. Mulligan. 2009. "Genetic Ancestry, Social Classification, and Racial Inequalities in Blood Pressure in Southeastern Puerto Rico." PLoS ONE 4(9):e6821.

Gullickson, Aaron. In press. "Essential Measures: Ancestry, Race, and Social Difference." American Behavioral Scientist.

Gullickson, Aaron and Ann Morning. 2011. "Choosing Race: Multiracial Ancestry and Identification.” Social Science Research 40(2):498-512.

Guo, Guang et al. 2014. "Genetic Bio-Ancestry and Social Construction of Racial Classification in Social Surveys in the Contemporary United States." Demography 51(1):141-72.

Hahn, Robert A., Benedict I. Truman, and Nancy D. Barker. 1996. "Identifying Ancestry: The Reliability of Ancestral Identification in the United States by Self, Proxy, Interviewer, and Funeral Director." Epidemiology 7(1):75-80.

Halder, Indrani et al. 2012. "Biogeographic Ancestry, Self-Identified Race, and AdmixturePhenotype Associations in the Heart SCORE Study." American Journal of Epidemiology 176(2):146-55.

Hannon, Lance, Robert DeFina, and Sarah Bruch. 2013. "The Relationship Between Skin Tone and School Suspension for African Americans." Race and Social Problems 5(4):281-95.

Harris, David R. 2002. In the Eye of the Beholder: Observed Race and Observer Characteristics. Population Studies Center Research Report No. 02-522.

Harris, David R. and Jeremiah Joseph Sim. 2000. An Empirical Look at the Social Construction of Race: The Case of Multiracial Adolescents. Population Studies Center. 
Harris, David R. and Jeremiah Joseph Sim. 2002. "Who Is Multiracial? Assessing the Complexity of Lived Race.” American Sociological Review 67(4):614-27.

Hilliar, Kirin F. and Richard I. Kemp. 2008. "Barack Obama or Barry Dunham? The Appearance of Multiracial Faces Is Affected by the Names Assigned to Them." Perception 37(10):1605-8.

Hill, Mark E. 2002. "Race of the Interviewer and Perception of Skin Color: Evidence from the Multi-City Study of Urban Inequality.” American Sociological Review 67(1):99-108.

Hitlin, Steven, J. Scott Brown, and Glen H. Elder. 2007. "Measuring Latinos: Racial Classifications and Self-Understandings." Social Forces 86:587-611.

Jenkins, Richard. 2008. Social Identity. 3rd edition. New York: Routledge.

Khanna, Nikki. 2004. “The Role of Reflected Appraisals in Racial Identity: The Case of Multiracial Asians." Social Psychology Quarterly 67(2):115-31.

Khanna, Nikki. 2010. “'If You're Half Black, You're Just Black': Reflected Appraisals and the Persistence of the One-Drop Rule." Sociological Quarterly 51(1):96-121.

Kreisman, Daniel and Marcos A. Rangel. 2014. "On the Blurring of the Color Line: Wages and Employment for Black Males of Different Skin Tones." Review of Economics and Statistics 97(1):1-13.

Kressin, Nancy R., Bei-Hung Chang, Ann Hendricks, and Lewis E. Kazis. 2003. "Agreement Between Administrative Data and Patients' Self-Reports of Race/Ethnicity." American Journal of Public Health 93(10):1734-39.

Liebler, Carolyn A., Sonya Rastogi, Leticia E. Fernandez, James M. Noon, and Sharon R. Ennis. 2014. America's Churning Races: Race and Ethnic Response Changes between Census 2000 and the 2010 Census.

Marcus, Gregory M. et al. 2010. "European Ancestry as a Risk Factor for Atrial Fibrillation in African Americans." Circulation 122(20):2009-15.

Monk, Ellis P. 2014. “Skin Tone Stratification among Black Americans, 2001-2003.” Social Forces 92(4):1313-37.

Monk, Ellis P., Jr. 2015. "The Cost of Color: Skin Color, Discrimination, and Health among African-Americans." American Journal of Sociology 121(2):396-444.

Nagaraj, Shyamala, Tey Nai-Peng, Ng Chiu-Wan, Lee Kiong-Hock, and Jean Pala. 2015. "Counting Ethnicity in Malaysia: The Complexity of Measuring Diversity." Pp. 143-74 in Social Statistics and Ethnic Diversity: Cross-National Perspectives in Classifications and Identity Politics, IMISCOE Research Series, edited by P. Simon, V. Piché, and A. A. Gagnon. New York: Springer International Publishing. 
Newby, C. Alison and Julie Dowling. 2007. "Black and Hispanic: Identification of Afro-Cuban Immigrants in the Southwest.” Sociological Perspectives 50:343-66.

Noymer, Andrew, Andrew M. Penner, and Aliya Saperstein. 2011. "Cause of Death Affects Racial Classification on Death Certificates." PLoS ONE 6(1):e15812.

Pauker, Kristin and Nalini Ambady. 2009. "Multiracial Faces: How Categorization Affects Memory at the Boundaries of Race." Journal of Social Issues 65(1):69-86.

Penner, Andrew M. and Aliya Saperstein. 2015. "Disentangling the Effects of Racial SelfIdentification and Classification by Others: The Case of Arrest." Demography 52(3):1017-24.

Perez, Marco V. et al. 2013. “African American Race but Not Genome-Wide Ancestry Is Negatively Associated with Atrial Fibrillation among Postmenopausal Women in the Women's Health Initiative." American Heart Journal 166(3):566-72.e1.

Perrin, Nicolas, Luc Dal, and Michel Poulain. 2015. "The Objective Approaches of Ethnic Origins in Belgium: Methodological Alternatives and Statistical Implications." Pp. 191208 in Social Statistics and Ethnic Diversity: Cross-National Perspectives in Classifications and Identity Politics, IMISCOE Research Series. New York: Springer International Publishing.

Rastogi, Sonya, Carolyn Liebler, and James Noon. In press. “An Outside View: What Do Observers Say about Others' Races and Hispanic Origins?” American Behavioral Scientist.

Rockquemore, Kerry Ann and David L. Brunsma. 2002. Beyond Black: Biracial Identity in America. Thousand Oaks, CA: Sage Publications.

Rodríguez, Clara E. 2000. Changing Race: Latinos, the Census, and the History of Ethnicity in the United States. New York: New York University Press.

Ronquillo, Jaclyn et al. 2007. "The Effects of Skin Tone on Race-Related Amygdala Activity: An fMRI Investigation." Social Cognitive and Affective Neuroscience 2(1):39-44.

Roth, Wendy D. 2010. "Racial Mismatch: The Divergence Between Form and Function in Data for Monitoring Racial Discrimination of Hispanics." Social Science Quarterly 91(5):1288-1311.

Roth, Wendy D. 2012. Race Migrations: Latinos and the Cultural Transformation of Race. Stanford, California: Stanford University Press.

Roth, Wendy D. 2015. "Studying Ethnic Schemas: Integrating Cognitive Schemas into Ethnicity Research through Photo Elicitation.” Pp. 89-118 in Studying Ethnic Identity: Methodological and Conceptual Approaches Across Disciplines, edited by C. E. Santos and A. J. Umaña-Taylor. Washington, D.C.: American Psychological Association. 
Retrieved October 20, 2015

(http://site.ebrary.com/lib/ubc/reader.action?docID=11044725\&ppg=89).

Roth, Wendy D. and Katherine Lyon. In press. "Genetic Ancestry Tests and Race: Who Takes Them, Why, and How Do They Affect Racial Identities?" in Reconsidering Race: CrossDisciplinary and Interdisciplinary Approaches, edited by K. Suzuki and von Vacano, Diego. New York: Oxford University Press.

Royal, Charmaine D. et al. 2010. "Inferring Genetic Ancestry: Opportunities, Challenges, and Implications." The American Journal of Human Genetics 86(5):661-73.

Saperstein, Aliya. 2006. "Double-Checking the Race Box: Examining Inconsistency between Survey Measures of Observed and Self-Reported Race." Social Forces 85:57-74.

Saperstein, Aliya. 2012. "Capturing Complexity in the United States: Which Aspects of Race Matter and When?" Ethnic and Racial Studies 35(8):1484-1502.

Saperstein, Aliya. 2013. "Representing the Multidimensionality of Race in Survey Research." in Mapping "Race": Critical Approaches to Health Disparities Research, edited by L. E. Gomez and N. Lopez. New Brunswick, N.J.: Rutgers University Press.

Saperstein, Aliya, Jessica M. Kizer, and Andrew M. Penner. In press. "Making the Most of Multiple Measures: Disentangling the Effects of Different Dimensions of Race in Survey Research.” American Behavioral Scientist.

Saperstein, Aliya and Andrew M. Penner. 2010. "The Race of a Criminal Record: How Incarceration Colors Racial Perceptions." Social Problems 57(1):92-113.

Saperstein, Aliya and Andrew M. Penner. 2012. "Racial Fluidity and Inequality in the United States." American Journal of Sociology 118(3):676-727.

Scholler, Martin. 2013. "The Changing Face of America - Photo Gallery." Retrieved September 23, 2015 (http://ngm.nationalgeographic.com/2013/10/changing-faces/schoellerphotography).

Smedley, Audrey and Brian D. Smedley. 2012. Race in North America: Origin and Evolution of a Worldview. 4th ed. Boulder, CO: Westview Press.

Smith, Tom W. 2001. Aspects of Measuring Race: Race by Observation vs. Self-Reporting and Multiple Mentions of Race and Ethnicity. National Opinion Research Center, GSS Methodological Report No. 93.

Snipp, C. Matthew. 1989. American Indians: The First of This Land. New York: Russell Sage.

Song, Miri and Peter Aspinall. 2012. "Is Racial Mismatch a Problem for Young 'mixed Race' People in Britain? The Findings of Qualitative Research.” Ethnicities 12(6):730-53. 
South, Scott J., Kyle Crowder, and Erick Chavez. 2005. "Migration and Spatial Assimilation among U.S. Latinos: Classical versus Segmented Trajectories.” Demography 42(3):497_ 521.

Stepanikova, Irena. 2010. “Applying a Status Perspective to Racial/ethnic Misclassification: Implications for Health.” Pp. 159-83 in Advances in Group Processes, vol. 27, Advances in Group Processes. Emerald Group Publishing Limited. Retrieved October 9, 2015 (http://www.emeraldinsight.com/doi/full/10.1108/S08826145\%282010\%290000027009).

Sugarman, J. R., R. Soderberg, J. E. Gordon, and F. P. Rivara. 1993. "Racial Misclassification of American Indians: Its Effect on Injury Rates in Oregon, 1989 through 1990.” American Journal of Public Health 83(5):681-84.

Telles, Edward. 2014. Pigmentocracies: Ethnicity, Race, and Color in Latin America. 1 edition. Chapel Hill, NC: The University of North Carolina Press.

Telles, Edward E. 2004. Race in Another America: The Significance of Skin Color in Brazil. Princeton, NJ: Princeton University Press.

Telles, Edward E. and Nelson Lim. 1998. "Does It Matter Who Answers the Race Question? Racial Classification and Income Inequality in Brazil.” Demography 35:465-74.

Telles, Edward and Tianna Paschel. 2014. "Who Is Black, White, or Mixed Race? How Skin Color, Status, and Nation Shape Racial Classification in Latin America." American Journal of Sociology 120(3):864-907.

Vargas, Nicholas. 2014. "Off White: Colour-Blind Ideology at the Margins of Whiteness." Ethnic and Racial Studies 37(13):2281-2302.

Vargas, Nicholas. 2015. "Latina/o Whitening? Which Latina/os Self-Classify as White and Report Being Perceived as White by Other Americans?" Du Bois Review: Social Science Research on Race 12(01):119-36.

Vargas, Nicholas and Kevin Stainback. In press. "Documenting Contested Racial Identities among Self-Identified Latina/os, Asians, Blacks, and Whites." American Behavioral Scientist.

Veenstra, Gerry. 2011. "Mismatched Racial Identities, Colourism, and Health in Toronto and Vancouver." Social Science \& Medicine 73(8):1152-62.

Viglione, Jill, Lance Hannon, and Robert DeFina. 2011. “The Impact of Light Skin on Prison Time for Black Female Offenders.” The Social Science Journal 48(1):250-58.

Waters, Mary C. 1990. Ethnic Options: Choosing Identities in America. Berkeley: University of California Press. 
West, Carmen N. et al. 2005. "Race and Ethnicity: Comparing Medical Records to SelfReports." Journal of the National Cancer Institute Monographs 35:72-74.

White, Karletta M. 2015. "The Salience of Skin Tone: Effects on the Exercise of Police Enforcement Authority." Ethnic and Racial Studies 38(6):993-1010.

Willadsen-Jensen, Eve C. and Tiffany A. Ito. 2006. "Ambiguity and the Timecourse of Racial Perception.” Social Cognition 24(5):580-606.

Williams, Gregory Howard. 1996. Life on the Color Line: The True Story of a White Boy Who Discovered He Was Black. New York, NY: Plume.

Wimmer, Andreas. 2008. "The Making and Unmaking of Ethnic Boundaries: A Multilevel Process Theory.” American Journal of Sociology 113(4):970-1022.

Xie, Yu and Kimberly Goyette. 1997. “The Racial Identification of Biracial Children with One Asian Parent: Evidence from the 1990 Census.” Social Forces 76(2):547-70. 
Figure 1: RACE Dimensions TyPOLOGY

\begin{tabular}{|c|c|c|c|c|}
\hline Dimension of Race & Description & Typical Measurement & Also described as & $\begin{array}{l}\text { Outcomes it may be } \\
\text { appropriate for } \\
\text { studying }\end{array}$ \\
\hline $\begin{array}{l}\text { RACIAL } \\
\text { IDENTITY }\end{array}$ & $\begin{array}{l}\text { Subjective self- } \\
\text { identification, not limited } \\
\text { by pre-set options. }\end{array}$ & $\begin{array}{l}\text { Open-ended self- } \\
\text { identification question }\end{array}$ & $\begin{array}{l}\text { "Internal race" (Roth 2010); } \\
\text { "Self-ID" (Scholler 2013); } \\
\text { "racial identification" } \\
\text { (Newby and Dowling 2007) }\end{array}$ & $\begin{array}{l}\text { Political mobilization; } \\
\text { assimilation; social } \\
\text { networks; voting; } \\
\text { residential decision- } \\
\text { making; attitudes }\end{array}$ \\
\hline $\begin{array}{l}\text { RACIAL SELF- } \\
\text { CLASSIFICATION }\end{array}$ & $\begin{array}{l}\text { The race you check on an } \\
\text { official form or survey } \\
\text { with constrained options } \\
\text { (e.g. the Census, college } \\
\text { financial aid form, the } \\
\text { GSS, etc.) }\end{array}$ & $\begin{array}{l}\text { Closed-ended survey } \\
\text { question }\end{array}$ & $\begin{array}{l}\text { "Expressed race" (Roth } \\
\text { 2010); "expressed internal } \\
\text { race" (Harris and Sim 2002); } \\
\text { "Census race" (Bailey 2008); } \\
\text { "self-reported race" } \\
\text { (Saperstein 2006); "racial } \\
\text { identification" (Saperstein } \\
\text { and Penner 2012) }\end{array}$ & $\begin{array}{l}\text { Demographic change; } \\
\text { vital statistics; disease } \\
\text { and illness rates } \\
\text { *Often used as a proxy } \\
\text { for Racial Identity }\end{array}$ \\
\hline $\begin{array}{l}\text { OBSERVED } \\
\text { RACE }\end{array}$ & $\begin{array}{l}\text { The race others believe } \\
\text { you to be }\end{array}$ & $\begin{array}{l}\text { Interviewer } \\
\text { classification }\end{array}$ & $\begin{array}{l}\text { "External racial identity" } \\
\text { (Harris and Sim 2002); } \\
\text { "racial classification" } \\
\text { (Saperstein and Penner } \\
\text { 2012); "racial identification" } \\
\text { (Xie and Goyette 1997) }\end{array}$ & $\begin{array}{l}\text { Discrimination; } \\
\text { socioeconomic } \\
\text { disparities; residential } \\
\text { segregation; criminal } \\
\text { justice indicators; health } \\
\text { care/service provision }\end{array}$ \\
\hline - Appearance-Based & $\begin{array}{l}\text { Observed race based on } \\
\text { readily observable } \\
\text { characteristics }\end{array}$ & $\begin{array}{l}\text { Interviewer } \\
\text { classification with } \\
\text { instructions to classify } \\
\text { on first observation }\end{array}$ & & $\begin{array}{l}\text { - Racial profiling; } \\
\text { discrimination in } \\
\text { public settings }\end{array}$ \\
\hline - Interaction-Based & $\begin{array}{l}\text { Observed race based on } \\
\text { characteristics revealed } \\
\text { through interaction (e.g. } \\
\text { language, accent, } \\
\text { surname) }\end{array}$ & $\begin{array}{l}\text { Interviewer } \\
\text { classification with } \\
\text { instructions to classify } \\
\text { after interaction or } \\
\text { survey }\end{array}$ & & $\begin{array}{l}\text { - Workplace } \\
\text { discrimination; } \\
\text { housing } \\
\text { discrimination; } \\
\text { language/accent-based } \\
\text { discrimination } \\
\end{array}$ \\
\hline
\end{tabular}


Figure 1 CONTINUED: RACE DIMENSIONS TyPOLOGY

\begin{tabular}{|c|c|c|c|c|}
\hline $\begin{array}{l}\text { REFLECTED } \\
\text { RACE }\end{array}$ & $\begin{array}{l}\text { The race you believe } \\
\text { others assume you to be }\end{array}$ & $\begin{array}{l}\text { "What race do most } \\
\text { people think you are?" }\end{array}$ & $\begin{array}{l}\text { "Perceived" race (Vargas } \\
\text { 2015) }\end{array}$ & $\begin{array}{l}\text { Self-identification } \\
\text { processes, perceived } \\
\text { discrimination } \\
\text { * Often used as a proxy } \\
\text { for Observed Race }\end{array}$ \\
\hline PHENOTYPE & Racial appearance & $\begin{array}{l}\text { Usually interviewer } \\
\text { classification }\end{array}$ & & $\begin{array}{l}\text { Discrimination; } \\
\text { socioeconomic } \\
\text { disparities; residential } \\
\text { segregation; criminal } \\
\text { justice indicators; health } \\
\text { care and service } \\
\text { provision }\end{array}$ \\
\hline - Color & Skin color & $\begin{array}{l}\text { Usually interviewer } \\
\text { classification on a likert } \\
\text { scale or color palette }\end{array}$ & & \\
\hline - Other features & $\begin{array}{l}\text { Hair texture or color, } \\
\text { nose shape, lip shape, eye } \\
\text { color }\end{array}$ & $\begin{array}{l}\text { Usually interviewer } \\
\text { classification on a series } \\
\text { of categorical variables }\end{array}$ & & \\
\hline $\begin{array}{l}\text { RACIAL } \\
\text { ANCESTRY }\end{array}$ & $\begin{array}{l}\text { The compiled racial } \\
\text { groups of your ancestors }\end{array}$ & & & \\
\hline - Known & $\begin{array}{l}\text { What you believe your } \\
\text { racial ancestry to be } \\
\text { based primarily on } \\
\text { family history }\end{array}$ & $\begin{array}{l}\text { Self-report, often open- } \\
\text { ended }\end{array}$ & & $\begin{array}{l}\text { Assimilation; racial } \\
\text { boundary formation; } \\
\text { social closure; disease } \\
\text { and illness rates }\end{array}$ \\
\hline - Genetic & $\begin{array}{l}\text { Deep ancestry indicated } \\
\text { by genetic testing }\end{array}$ & $\begin{array}{l}\text { Analysis of ancestry } \\
\text { informative markers by } \\
\text { researchers or direct-to- } \\
\text { consumer companies }\end{array}$ & $\begin{array}{l}\text { "Genetic ancestry" (Royal et } \\
\text { al. 2010); "Genome-wide } \\
\text { ancestry" (Perez et al. 2013); } \\
\text { "Ancestry inference" } \\
\text { (Bolnick 2008) }\end{array}$ & $\begin{array}{l}\text { Self-identification } \\
\text { processes }\end{array}$ \\
\hline
\end{tabular}

Note: This figure builds on an earlier typology in Roth (2010) and benefitted from the discussions of the Measuring the Diverging Components of Race Workshop at Texas A\&M University in June 2014. 
Figure 2: Integrated Model of Racial Multidimensionality, Fluidity, and Boundary Processes

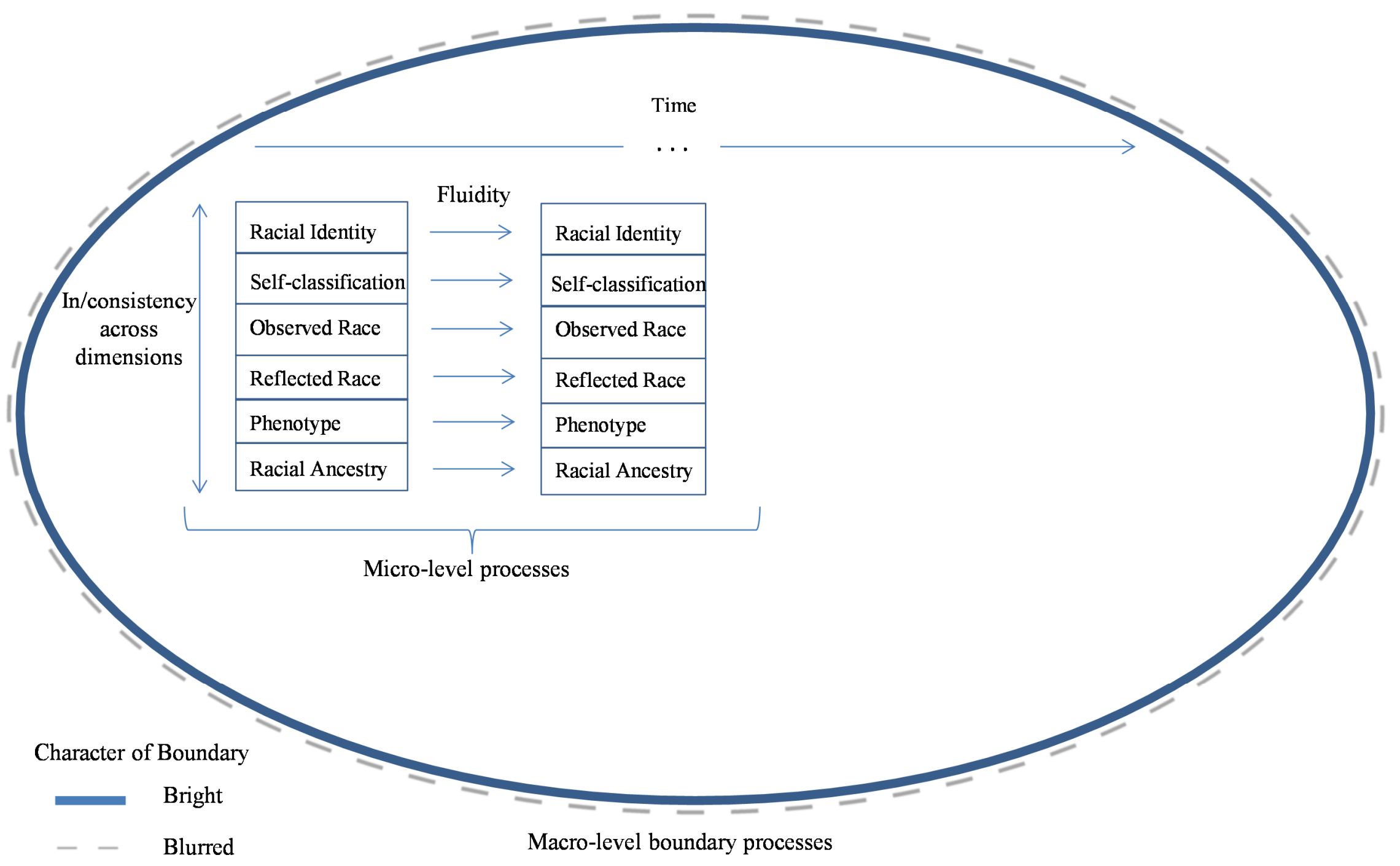


WENDY D. ROTH is Associate Professor in the Department of Sociology at the University of British Columbia. Address: Department of Sociology, 6303 N.W. Marine Drive, Vancouver, BC V6T 1Z1, Canada. Email: wendy.roth@ubc.ca 